\title{
Adverse selection and the market for annuities
}

\author{
Oded Palmon · Avia Spivak
}

Received: 11 May 2004/Revised: 4 February 2007/Published online: 10 July 2007

(C) The Geneva Association 2007

\begin{abstract}
Adverse selection is often blamed for the malfunctioning of the annuities market. We simulate the impact of adverse selection on the consumption allocation of annuitants under alternative parameter values, and explore the resulting welfare implications. We show that, for most parameter values, the welfare losses associated with equilibriums that are subject to adverse selection correspond to a loss of wealth of around one percent in a first-best equilibrium. These losses are smaller than the corresponding losses associated with equilibriums with no access to an annuity market by an order of magnitude of ten. The existence of substitutes for annuities such as a bequest motive or a social security system intensifies the adverse selection but reduces its welfare impact.
\end{abstract}

Keywords Adverse selection · Annuities - Insurance · Information · Social Security reform · Defined Benefits · Defined Contribution

JEL Classification $\mathrm{H} 55 \cdot \mathrm{G} 22 \cdot \mathrm{G} 28$

\section{Introduction}

The functioning of the market for private annuities has received renewed attention recently. Annuities provided institutionally, by social security systems and

O. Palmon $(\bowtie)$

Department of Finance and Economics, Rutgers Business School - Newark and New Brunswick, Rutgers University, New Brunswick, NJ, USA

e-mail: palmon@business.rutgers.edu

A. Spivak

Department of Economics, Ben-Gurion University, Beer-Sheva, Israel

A. Spivak

Van Leer Institute, Jerusalem, Israel 
occupational pension plans, comprise a significant fraction of the wealth of the elderly. In contrast, private annuities are rarely found in their portfolios (see, for example, Dushi and Webb [2004]). This behavior is in contrast to the conclusions of Davidoff et al. [2005] that an individual without a bequest motive should annuitize all her wealth if an annuity market operates.

The literature suggests three types of reasons for this avoidance of annuitization. First, the institutionally provided annuities might cover more than is optimally desired by most individuals. Bernheim [1991] finds evidence for the existence of a strong bequest motive, and concludes that many individuals are already overannuitized in the Social Security system.

Second, in comparison with institutionally provided plans, the private market for annuities does not function well due to adverse selection. Akerloff [1970] introduced the process by which a market may disappear due to asymmetric information. Eichenbaum and Peled [1987], among others, imply that asymmetric information may be a major reason for the small size of the annuity market. This view is supported by the empirical findings of Warshawsky [1988] and Friedman and Warshawsky [1990] who document that the longevity of individuals covered by private annuities exceeds the population's average. ${ }^{1}$ Third, the private annuities market may malfunction also because of other reasons such as high administrative and marketing costs (Diamond [1994]) or the inflexibility of the products in the annuities markets. For example, Yagi and Nishigaki [1993] point out that the individuals who wish to purchase a decreasing annuity (because their subjective time preference is higher than the rate of return) are forced to monetize part of their wealth if decreasing annuities are not available in the market. Finally, the assumption of full rationality has also been challenged recently (see the articles in Aaron [1999] and in Mitchell and Utkus [2004]). ${ }^{2}$

The first two alternative reasons suggest different policy consequences for the privatization of The Social Security system in the U.S. and elsewhere. Ideally, the reformers would like to introduce a private Defined Contribution (DC) system that replaces the Social Security system, and allows individuals to determine the amount of retirement accumulation they annuitize. If the first reason holds, the abolition of public annuities should crowd in private annuities and create a thriving market in them. ${ }^{3}$ By contrast, if the second reason holds, privatization may cause private markets for annuities to malfunction.

If the problem with private annuity markets is adverse selection, the universality of the social security system is a valid solution. ${ }^{4}$ The magnitude of the adverse selection problem is thus of special interest in the context of the public debate

\footnotetext{
${ }^{1}$ See, also, Poterba [2001] and Finkelstein and Poterba [2002]. The lower mortality rates of annuitants, compared with those for the general population, are also evident in, among others, Mitchell et al. [1999].

${ }^{2}$ Market incompleteness may be a fourth reason for the weakness of the annuity markets. (See: Davidoff et al. [2005] and Turra and Mitchell [2004]).

${ }^{3}$ The Singaporean case is somewhere in between these positions: the market for annuities is private, but annuitization of benefits is mandatory. See: Fong [2002].

${ }^{4}$ Stiglitz [1988, p. 332] states: "Adverse selection may provide part of the explanation for high premiums charged for annuities. The government, however, can force all individuals to purchase the insurance, and thus avoid the problem of adverse selection."
} 
regarding the roles of the public and private sectors in the accumulation of retirement savings and the provision of retirement income. ${ }^{5}$ Assessing the magnitude of the adverse selection problem is also important for the welfare implications of the recent move from Defined Benefit (DB) pension plans to Defined Contribution (DC) pension plans. DB pension plans are usually contracted at a relatively young age, when insureds have little information regarding their survival probabilities. Thus, these contracts should be more immune to the adverse selection problem than DC plans that allow each participant to choose between lump sum and annuity distributions at the time of retirement. A severe adverse selection problem may justify the imposition of restrictions on the ability of owners of DC accounts to obtain a lump sum, or incentives to annuitize their portfolio, at the time of retirement. ${ }^{6}$

In this paper we obtain insights into the importance of adverse selection in annuity markets by simulating consumer behavior and obtaining her expected utility under alternative settings. These models include a two periods base case with no bequest motive, a mutliperiod model, a model with a bequest motive and a model with social security benefits. In all these models, we find that the welfare loss due to adverse selection is equivalent to that of a one percent wealth loss, and is about one tenth of the corresponding impact of a lack of access to an annuity market. ${ }^{7}$

A closer inspection reveals two classes of models: those without and with either a bequest motive or a social security system. In the absence of a bequest motive and a social security system there is very little adverse selection under most of the parameter combinations: the price of annuities and the welfare of annuitants are very close to those under perfect competition. In these models, the consumer has no alternative for the annuities market: buying an annuity is better than a regular bond for all consumers. Thus, no consumer leaves the market, the domino efffect of the 'lemons' market is avoided, and the market operates very efficiently.

In contrast, in models with bequest or a social security system the price of annuities deviates more widely from perfect competition equilibrium. Moreover, if the bequst motive is suficiently strong (or if the social security benefits are high enough), the annuity market may even disappear, as in the seminal 'lemons' market [Akerloff, 1970]. In these models, the availability of alternatives for private annuities (in the form of mandatory social security or voluntary bequests) reduces the demand for annuities. Because low-survivorship individuals reduce their demand for annuities by a larger percentage than high-survivorship individuals, these alternatives for private annuities increase the impact of adverse selection on annuity prices. It should also be noted that adverse selection increases the bequests of low-survivorship individuals and thus exacerbates the effect of a bequest motive

\footnotetext{
${ }^{5}$ Note that this study focuses on the provision of annuity income, not on the accumulation of retirement savings. Kotlikoff et al. [2004] focus on the assets accumulation stage, discussing the impact of adverse selection on social security privatization. Their discussion attributes opting out of the system to income and age, and is not based on information.

${ }^{6}$ Poterba [2001] shows that a requirement to annuitize at least a fraction of the accumulation in DC plans may also mitigate the impact of adverse selection.

${ }^{7}$ Note that the impact due to the lack of an annuity market is modest in comparison to the results in Brown [2003].
} 
on the annuities market. However, because individuals can use substitutes to private annuities, the total impact on expected welfare is still small.

Nonetheless, our simulations indicate that, surprisingly, equilibria with a social security system may be associated with lower welfare level than the equilibrium with no social security system. The intuition is as follows. It is obvious that a social security system that provides exactly all the desired retirement income of its members yields the first-best allocation which is preferred over the adverse selection equilibrium without a social security system. However, most social security systems provide only fractions of the desired retirement incomes of their participants. Thus, individuals may want to purchase additional annuities in private annuity markets. While the provision of fairly priced annuities enhances welfare, the existence of a modest social security system also reduces welfare because it aggravates the adverse selection problem in private annuity markets. Our simulations indicate that the latter dominates the former for the range of social security benefits in most economies.

Our quantitative simulations findings are similar to the conclusions in Mitchell et al. [1999] and Walliser [2000]. In their empirical study, Mitchell et al. find that the loss from adverse selection is much smaller than that from having no access to the annuities market, and hence provides no explanation for the avoidance of the annuities markets. They show that the cost of an annuity in the U.S. exceeds its fair actuarial value by six to ten percent if the annuitants' life tables are used. However, these margins provide only an upper limit for the impact of adverse selection because, as Mitchell et al. note, the margins also include marketing costs, corporate overheads, and profits. James and Vittas [2001] find similar figures in an international comparison. Another international comparison of the estimates of adverse selection in annuities is provided by Mitchell and McCarthy [2002] who use a different methodology. Walliser [2000] concludes that adverse selection increases annuity prices by seven to ten percent, and that the privatization of The Social Security system may reduce these prices by between two and three percent. Finkelstein and Poterba [2004] find that adverse selection is reflected in the association between mortality rates and the timing of annuity cash flows, but not between mortality rates and contract size. Thus, the current paper provides a theoretical support to the findings of these empirical papers.

The rest of the paper is organized as follows. In Sect. 2 we present the basic twoperiod model. In Sect. 3 we simulate the insured's expected utility under the adverse selection equilibrium and compare that level to the expected utility levels obtained under two extreme allocations: a first-best allocation and an allocation with no access to annuity markets. In Sect. 4 we present the multiperiod model and simulate its asymmetric information equilibrium. Section 5 deals with the impacts of the existence of a bequest motive, and Sect. 6 with the impacts of a social security system. Section 7 concludes the paper.

\section{Adverse selection in annuity markets}

We assume that at a young age insureds believe that their expected longevity equals the population's average. However, their information at the time of retirement is more precise. We explore three allocations and compare their expected welfare 
levels. First is the first best allocation in which individuals determine their annuity purchase when they have no information regarding their longevity. This allocation may be obtained by purchasing a "precommitment" annuity contract that is initiated at a relatively young age, before the information on longevity is revealed. It corresponds to a deferred annuity contract, or to a DB plan. In contrast, the second allocation is associated with annuity contracts that are purchased at the time of retirement (similar to a DC plan). In this "asymmetric information" equilibrium, annuity contracts are assumed to be purchased when the longevity information is known only to the insured. We evaluate the expected welfare loss due to the asymmetric information by calculating the ratio between the wealth levels that yield identical expected utility under the two allocations. We contrast the welfare loss due to the asymmetric information with a corresponding welfare loss due to the absence of access to the annuity market which underlies our third allocation.

We first present a base model in which insureds live for one or two periods, have no bequest motive, and have no social security benefits. ${ }^{8} \mathrm{We}$ assume that they consume at the end of each period, at dates $t=1,2$. In the first period they live and consume with certainty, but their survival probability through period 2 is $q<1$. We assume two types of insureds: high survival type and low survival type (denoted as $\mathrm{H}$-insureds and L-insureds, respectively) with $q_{H}>q_{L}$ and $\left(q_{H}+q_{L}\right) / 2=1 / 2$. At date $t=0$ insureds know only that they may be of either type with a probability of $1 /$ 2, but between $t=0$ and $t=1$ they find out their type. ${ }^{9}$ We denote by $C_{1}$ and $C_{2}$ the consumption levels at the end of periods 1 and 2 , respectively.

The insureds maximize a time separable expected utility $u(c), u^{\prime}>0$, $u^{\prime \prime}<0, u^{\prime}(0)=\infty$, with a time preference factor $\beta<1 .{ }^{10}$ Consistent with the absence of a bequest motive, we assume that they derive utility from consumption at date $t=2$ only if they survive. The interest rate is denoted by $r$. The exposition and interpretation of our results is simplified by assuming that $\beta(1+r)=1$. $^{11}$ Thus, the insured's expected utility is: $u\left(C_{1}\right)+q \beta u\left(C_{2}\right)$, where $q$ is the probability known to her at the time the allocation is determined. At $t=0$ insureds use the probability $q=0.5$, while at $t=1$ they use the probabilities $q_{H}$ or $q_{L}$ according to their type. We assume that competition in the insurance market guarantees that insurers balance actuarially.

\footnotetext{
8 The absence of a bequest motive is consistent with the findings in Altonji et al. [1997]. It also simplifies the initial presentation. In Sect. 5 we incorporate a bequest motive and demonstrate that our main results are robust to this change.

${ }^{9}$ Our results are robust to the simplifying assumptions that the probability of each type is 0.5 and that $q_{H}$ and $q_{L}$ are symmetric around 0.5. Further details are provided below (see the end of Sect. 3 and Table A1).

${ }^{10}$ Our expected utility specification is standard in the annuity literature, following the seminal contribution of Yaari [1965]. While the survival probabilities appear linearly in this specification, Epstein and Zin [1989] present an interesting model that uses a recursive (but not necessarily expected) utility specification to analyze a multi-period investment/consumption decision for an individual with a certain lifetime. The disentanglement of intra period risk aversion and inter period substitution allows better fit of a model to the data. In contrast to Epstein and Zin [1989], the lifetime in our model is uncertain, and the assets are risk-free bonds and annuities that have no intra period risk. Thus, their specification is not advantageous in our model.

${ }^{11}$ This assumption implies that an individual who lives with certainty would choose identical consumption levels at dates $t=1$ and $t=2$.
} 
Insureds can use two assets as saving vehicles: a non-annuitized, financial asset $D$ and an annuity $A$, with the respective prices $P_{D}$ and $P_{A}$. The annuity pays out one consumption unit in the second period contingent upon survival, while the nonannuitized financial asset pays out one consumption unit unconditionally. Assuming competition between insurers and no overhead costs, $P_{D}=1 /(1+r)$ and $P_{A}=q /(1+r)$, where $q$ is the insurer's estimate of the survival probability. The price of the annuity is lower than that of the non-annuitized financial asset, because $q<1$; hence, the only rationale for holding a non-annuitized asset in a two-period model is the desire to leave a bequest in the event of death before $t=2$. $^{12} \mathrm{We}$ thus simplify the presentation in this paper by ignoring the non-annuitized asset in all the two-period models in which individuals have no bequest motive. Next we presentfor each allocation - the information structure, the annuity contract and the resulting consumption levels.

\subsection{Allocation 1: Full precommitment contract}

Each insured purchases at date $t=0$ the consumption good for dates $t=1$ and $t=2$, denoted as $C_{1}$ and $C_{2}$. Consumption at $t=1$ takes place with certainty, but at date $t=2$ it is contingent upon the survival of the insured. The timing of information arrival and individual actions is summarized in the following time line:

\begin{tabular}{|c|c|c|c|c|}
\hline$t=0$ & & $\mathrm{t}=1$ & & $t=2$ \\
\hline $\begin{array}{l}\text { Purchases an } \\
\text { annuity }\end{array}$ & $\begin{array}{l}\text { Type is } \\
\text { revealed }\end{array}$ & $\begin{array}{c}\text { Consumes } \\
\mathrm{C}_{1}\end{array}$ & $\begin{array}{l}\text { Longevity is } \\
\text { revealed }\end{array}$ & $\begin{array}{c}\text { Consumes } \mathrm{C}_{2} \text { if } \\
\text { survives }\end{array}$ \\
\hline
\end{tabular}

Because the type information is not known at the time the contract is initiated, at date $t=0$, both insureds and insurers use $1 / 2$ (the average survival probability) as the relevant probability in calculating the expected utility, the budget constraint, and the annuity price. All insureds buy the same annuity amount, and thus the annuity price is: $P_{A}=0.5 /(1+r)$. The insured's problem is thus:

$$
\begin{gathered}
\max u\left(C_{1}\right)+0.5 \beta u\left(C_{2}\right) \\
\text { s.t. } C_{1}+P_{A} C_{2}=W,
\end{gathered}
$$

where $W$ is the wealth at the end of period 1. Later, we normalize the units and set $W=1$. The conditions for the insured's optimal consumption imply that the standard result of equal consumption in both periods applies. Hence we obtain:

$$
C_{1}=C_{2}=W /(1+0.5 /(1+r))=C_{P R} \text {. }
$$

\footnotetext{
12 In a multi-period model individuals may purchase a non-annuitized asset to generate a decreasing consumption pattern.
} 
The expected utility of this contract, denoted by EUpr, is:

$$
E U p r=(1+0.5 \beta) u\left(C_{P R}\right) .
$$

\subsection{Allocation 2: Adverse selection - asymmetric information}

The equilibrium under this contract is assumed to be a pooling equilibrium, where insurers cannot distinguish between the two types of insureds. In this equilibrium insurers cannot observe the total quantities of annuities bought by each individual (from various insurers), and thus a separating equilibrium (in which annuity prices are positively related to the total quantities purchased) is not possible. Although not modeled explicitly, income variation may also hinder the insurers' ability to infer the insured's type. ${ }^{13}$

The timing of information arrival and individual actions under the asymmetric information contract is:

\begin{tabular}{|c|c|c|c|c|}
\hline $\mathrm{t}=0$ & & $\mathrm{t}=1$ & & $\mathrm{t}=2$ \\
\hline $\begin{array}{l}\text { Type is revealed to insured but insurer } \\
\text { cannot use it }\end{array}$ & $\begin{array}{l}\text { Purchases an } \\
\text { annuity }\end{array}$ & $\begin{array}{c}\text { Consumes } \\
\mathrm{C}_{1}\end{array}$ & $\begin{array}{l}\text { Longevity is } \\
\text { revealed }\end{array}$ & $\begin{array}{l}\text { Consumes } \mathrm{C}_{2} \text { if } \\
\text { survives }\end{array}$ \\
\hline
\end{tabular}

Insureds decide on their purchases after their types are revealed. However, insurers cannot condition the premium on the insured's type due to asymmetric information or legal constraints. Thus, insurers charge all insureds an equal annuity price, $q_{A D}$, which reflects a weighted average of the survival probabilities. The weights for $q_{H}$ and $q_{L}$ are $C_{2 H}$ and $C_{2 L}$, respectively. Note that in such pooling equilibrium, the L-insureds subsidize the $\mathrm{H}$-insureds because the annuity price is higher than the fair price for the L-insureds, but lower than the fair price for the $\mathrm{H}$-insureds. Consequently, the L-insureds purchase less annuity than the $\mathrm{H}$-insureds, causing the weighted average $q_{A D}$ to exceed $1 / 2$. Setting $W$ to equal 1 , the insured's problem is:

$$
\begin{gathered}
\max u\left(C_{1 i}\right)+q_{i} \beta u\left(C_{2 i}\right) \\
\text { s.t. } C_{1 i}+C_{2 i} q_{A D} /(1+r)=1 \\
i=H, L .
\end{gathered}
$$

The Langrangean for this case is:

$$
L_{i}=u\left(C_{1 i}\right)+q_{i} \beta u\left(C_{2 i}\right)-\lambda_{i}\left[C_{1 i}+C_{2 i} q_{A D} /(1+r)-1\right], i=H, L .
$$

The first order conditions for the optimal consumption allocation are:

\footnotetext{
13 Abel [1986], likewise, uses a pooling equilibrium. Eichenbaum and Peled [1987] use a RothschildStiglitz quantity-constrained separating equilibrium.
} 


$$
\begin{gathered}
u^{\prime}\left(C_{1 i}\right)=\lambda_{i} \\
u^{\prime}\left(C_{2 i}\right)=\lambda_{i} q_{A D} / q_{i} \\
C_{1 i}+C_{2 i} q_{A D} /(1+r)=1 \\
i=H, L .
\end{gathered}
$$

In addition to these first order conditions, competition implies that the equilibrium solution should satisfy the zero profit condition for the insurer:

$$
\pi=\left(q_{A D} /(1+r)\right)\left(0.5 C_{2 L}+0.5 C_{2 H}\right)-\left(q_{L} 0.5 C_{2 L}+q_{H} 0.5 C_{2 H}\right) /(1+r)=0 .
$$

The annuities $C_{2 L}$ and $C_{2 H}$ are purchased at the same price $P_{A}=q_{A D} /(1+r)$. The first term in the above expression represents the revenue of the insurer, while the second term represents his expected capitalized expenses.

Equivalently:

$$
q_{A D}=\left(q_{L} C_{2 L}+q_{H} C_{2 H}\right) /\left(C_{2 L}+C_{2 H}\right)
$$

\subsection{Allocation 3: No access to the insurance market}

In this case, the insured's problem is:

$$
\begin{gathered}
\max u\left(C_{1 i}\right)+q_{i} \beta u\left(C_{2 i}\right) \\
\text { s.t. } C_{1 i}+C_{2 i} /(1+r)=1 \\
i=H, L .
\end{gathered}
$$

The Langrangean for this case is:

$$
L_{i}=u\left(C_{1 i}\right)+q_{i} \beta u\left(C_{2 i}\right)-\lambda_{i}\left[C_{1 i}+C_{2 i} /(1+r)-1\right], i=H, L .
$$

The first order conditions for the optimal consumption allocation in this case are:

$$
\begin{gathered}
u^{\prime}\left(C_{1 i}\right)=\lambda_{i} \\
u^{\prime}\left(C_{2 i}\right)=\lambda_{i} / q_{i} \\
C_{1 i}+C_{2} /(1+r)=1 \\
i=H, L .
\end{gathered}
$$

Brugiavini [1993] demonstrates that the precommitment contract is superior to any other contract. This is because the precommitment contract provides insurance against both the uncertainty of the insured's type and her longevity. This is also reminiscent of Hirshleifer's [1971] model, where the revelation of information reduces welfare because it destroys the insurance market. ${ }^{14}$ Eckwert and Zilcha [2003] discuss two opposing effects on the efficiency of the market. First, the above

\footnotetext{
${ }^{14}$ Sheshinski [2003] also concludes that early contracting is preferred to annuitizing at retirement. However, he focuses on the optimal retirement age and the unintended bequest of individuals who die prior to their retirement date. In our model, retirement age is given exogenously, and no one dies prior to that date.
} 
mentioned 'Hirshleifer effect' limits the risk sharing opportunities in insurance markets and thus reduces welfare. Second, the 'Blackwell effect' improves individual decisions and thus enhances welfare. Crocker and Snow [1992] obtain two similar opposing welfare effects in a signaling economy. Additional information reduces the unproductive signaling and allows finer sorting for some agents, while it increases the signaling costs for other agents and eliminates some feasible allocation with low signaling costs.

\section{Simulation of the two-period model}

In this section we simulate the expected utility of a representative individual under the three alternative allocations: a precommitment annuity contract, an annuity contract that is subject to adverse selection, and no access to an annuity market. We demonstrate that the expected utility under an annuity contract that is subject to adverse selection is close to the expected utility under a precommitment contract, and much larger than the expected utility when individuals have no access to the annuity market. We conclude that adverse selection is not a major reason for the malfunctioning of the annuity market.

Our basic example is the CRRA utility function $u(C)=[1 /(1-\gamma)] C^{1-\gamma}$, where $\gamma>0$ is the measure of relative risk aversion. ${ }^{15} \mathrm{We}$ simplify the presentation by assuming that $1 /(1+r)=\beta=1 / 2{ }^{16}$ The latter may correspond to a rate of $6 \%$ compounded annually during a 12 -year period (11.9 is the more precise number), or to a rate of $4 \%$ compounded during an eighteen year period (17.67 is the more precise number). Thus, if the appropriate interest rate is between 4 and 6 percent, our twoperiod model covers between twenty-four and thirty-six years of possible retirement. ${ }^{17}$

As indicated by Eqs. 1 and 2, the utility of the precommitment allocation is:

$$
E U p r=1.25[1 /(1-\gamma)](0.8 W)^{1-\gamma}=[1 /(1-\gamma)] 0.8^{-\gamma}(W)^{1-\gamma} .
$$

We obtain a quantitative measure of the utility loss by presenting in Table 1 the pre-commitment wealth levels that provide the same expected utility levels as provided by wealth of $\$ 1$ under the adverse selection contract and in the absence of access to annuity markets for alternative values of $q_{H}, q_{L}$ and $\gamma$. We refer to these measures as the Equivalent Variations (EVs). Note that under the CRRA utility function each EV represents the ratio between the required wealth level under the precommitment contract and under the allocation that is associated with the EV for any fixed utility level. An increase in $q_{H}$ represents a mean preserving spread of the survival probabilities, since $q_{L}=1-q_{H}$. Thus, adverse selection EVs should be

\footnotetext{
${ }^{15}$ Brown [2003], Feldstein and Ranguelova [2001] and Walliser (2000) use the same utility specification in their simulations.

${ }^{16}$ Our results do not depend on this simplifying assumption. Further details are provided below (see the end of Sect. 3 and Table A1).

${ }^{17}$ Under this interpretation the consumption at $t=1$ is the lump sum equivalent of the 12-18 years that immediately follow retirement, and the consumption at $t=2$ (which is contingent upon survival) is the lump sum equivalent of the following 12-18 years.
} 
Table 1 Equivalent variations of adverse selection-asymmetric information allocation

\begin{tabular}{llllllllll}
\hline$q_{H} / \gamma$ & & 0.5 & 1.5 & 2 & 2.5 & 3 & 4 & 5 & 6 \\
\hline 0.55 & $\mathrm{EV}_{\text {ad }}$ & 0.9984 & 0.9995 & 0.9996 & 0.9997 & 0.9997 & 0.9998 & 0.9998 & 0.9999 \\
& $\mathrm{EV}_{\text {no-ad }}$ & 0.9009 & 0.8595 & 0.8533 & 0.8494 & 0.8468 & 0.8435 & 0.8415 & 0.8402 \\
0.60 & $\mathrm{EV}_{\text {ad }}$ & 0.9941 & 0.9979 & 0.9984 & 0.9987 & 0.9989 & 0.9992 & 0.9994 & 0.9995 \\
& $\mathrm{EV}_{\text {no-ad }}$ & 0.9036 & 0.8611 & 0.8545 & 0.8505 & 0.8477 & 0.8442 & 0.8421 & 0.8406 \\
0.65 & $\mathrm{EV}_{\text {ad }}$ & 0.9882 & 0.9953 & 0.9964 & 0.9971 & 0.9976 & 0.9982 & 0.9985 & 0.9988 \\
& $\mathrm{EV}_{\text {no-ad }}$ & 0.9080 & 0.8638 & 0.8567 & 0.8522 & 0.8492 & 0.8453 & 0.8430 & 0.8414 \\
0.70 & $\mathrm{EV}_{\text {ad }}$ & 0.9820 & 0.9919 & 0.9937 & 0.9949 & 0.9957 & 0.9968 & 0.9974 & 0.9978 \\
& $\mathrm{EV}_{\text {no-ad }}$ & 0.9142 & 0.8678 & 0.8598 & 0.8549 & 0.8514 & 0.8471 & 0.8444 & 0.8426 \\
0.75 & $\mathrm{EV}_{\text {ad }}$ & 0.9771 & 0.9876 & 0.9903 & 0.9921 & 0.9933 & 0.9949 & 0.9959 & 0.9966 \\
& $\mathrm{EV}_{\text {no-ad }}$ & 0.9223 & 0.8732 & 0.8642 & 0.8585 & 0.8545 & 0.8494 & 0.8463 & 0.8442 \\
0.80 & $\mathrm{EV}_{\text {ad }}$ & 0.9743 & 0.9828 & 0.9863 & 0.9887 & 0.9904 & 0.9926 & 0.9940 & 0.9950 \\
& $\mathrm{EV}_{\text {no-ad }}$ & 0.9321 & 0.8805 & 0.8701 & 0.8634 & 0.8587 & 0.8527 & 0.8489 & 0.8464 \\
0.85 & $\mathrm{EV}_{\text {ad }}$ & 0.9742 & 0.9775 & 0.9816 & 0.9846 & 0.9868 & 0.9898 & 0.9917 & 0.9930 \\
& $\mathrm{EV}_{\text {no-ad }}$ & 0.9438 & 0.8901 & 0.8780 & 0.8700 & 0.8644 & 0.8571 & 0.8526 & 0.8495 \\
0.90 & $\mathrm{EV}_{\text {ad }}$ & 0.9768 & 0.9723 & 0.9765 & 0.9799 & 0.9825 & 0.9862 & 0.9887 & 0.9904 \\
& $\mathrm{EV}_{\text {no-ad }}$ & 0.9573 & 0.9032 & 0.8891 & 0.8795 & 0.8726 & 0.8635 & 0.8578 & 0.8539 \\
0.95 & $\mathrm{EV}_{\text {ad }}$ & 0.9821 & 0.9677 & 0.9707 & 0.9740 & 0.9770 & 0.9815 & 0.9846 & 0.9868 \\
& $\mathrm{EV}_{\text {no-ad }}$ & 0.9727 & 0.9227 & 0.9062 & 0.8945 & 0.8858 & 0.8740 & 0.8664 & 0.8612 \\
\hline
\end{tabular}

For each combination of the survival probability of the H-insureds $\left(q_{H}\right)$ and the measure of relative risk aversion $(\gamma)$, the entries represent the wealth levels under the precommitment contract that yield the same welfare as one unit of wealth under the Asymmetric Information contract $\left(\mathrm{EV}_{\mathrm{ad}}\right)$ and when individuals have no access to annuity markets $\left(\mathrm{EV}_{\text {no-ad }}\right)$, respectively. In all cases the high and low types are equally likely and the survival probabilities of the $\mathrm{H}$-insureds and L-insureds add up to 1

negatively related to $q_{H}$. Higher values of $\gamma$ should be associated with a mitigated tendency to take advantage of private information, but also with a larger required wealth compensation for a given percentage departure from the first best. Thus, adverse selection EVs may not be monotonically related to $\gamma$.

The absence of access to an annuity market reduces expected welfare most when the uncertainty at the time of retirement is large (i.e., when $q_{H}$ is close to 0.5 ), and when consumption in one period is a poor substitute for consumption in the other period (i.e., when $\gamma$ is relatively large). Thus, the equivalent variations in the absence of access to annuity markets should be positively related to $q_{H}$ and negatively related to $\gamma$. A comparison of the adverse selection and no access Equivalent Variations in Table 1 indicates that, for most parameter values, the loss of welfare due to adverse selection is equivalent to a loss of about one percent of wealth (and in many cases less than that), while the corresponding loss due to a lack of access to an annuity market is equivalent to a loss of ten to fifteen percent of wealth. We conclude that, except for the cases where individuals face little uncertainty at retirement and can substitute consumption levels between periods, the loss of expected welfare due to a lack of access to an annuity market is more than ten times larger than the loss of welfare due to adverse selection. As indicated in footnotes 9 and 16, we examine the Equivalent Variations also for parameter 
combinations that differ from those under our simplifying assumptions. In Table A1 (in the Appendix), we present the Equivalent Variations for alternative values of the discount rate, the type probabilities and the survivorship probabilities. We conclude that our results are maintained even when the paraments do not comply with the assumptions we make in order to simplify the presentation.

In addition to the equivalent welfare measures, the literature has used the Money's Worth Ratio (MWR) to assess the impact of adverse selection on insureds. The MWR is the expected capitalized value of the income stream ensuing from a one-dollar annuity purchased by an individual with average survival probabilities (where "average" may refer to the general population or to a subset). Under the adverse selection allocation, $\mathrm{MWR}=0.5 / q_{A D}$. The MWR values for some combinations of the risk aversion and survival probabilities and the corresponding consumption levels are presented in Table 2.

Note that under the precommitment contract, MWR $=1$. The MWR values for reasonable values of the degree of risk aversion (between 2 and 4), and for values of $q_{H}$ between 0.7 and 0.8 , are consistent with the six to ten percent excess of the cost of an annuity over its fair actuarial value that are documented in the literature (see, for example, Mitchell et al. [1999], where annuitants' life tables are used).

Table 2 Money's worth ratios and consumption levels under the asymmetric information contract for various levels of risk aversion and survival probabilities

\begin{tabular}{|c|c|c|c|c|c|c|c|}
\hline$\gamma$ & $q_{H}$ & $q_{A D}$ & MWR & $C_{1 H}$ & $C_{1 L}$ & $C_{2 H}$ & $C_{2 L}$ \\
\hline 0.5 & 0.75 & 0.6848 & 0.7301 & 0.7089 & 0.9564 & 0.8502 & 0.1275 \\
\hline 1.5 & 0.75 & 0.5717 & 0.8746 & 0.7448 & 0.8586 & 0.8926 & 0.4947 \\
\hline 2.0 & 0.75 & 0.5542 & 0.9022 & 0.7562 & 0.8431 & 0.8797 & 0.5663 \\
\hline 2.5 & 0.75 & 0.5435 & 0.9199 & 0.7639 & 0.8339 & 0.8689 & 0.6112 \\
\hline 3.0 & 0.75 & 0.5363 & 0.9322 & 0.7693 & 0.8279 & 0.8603 & 0.6419 \\
\hline 4.0 & 0.75 & 0.5273 & 0.9482 & 0.7764 & 0.8205 & 0.8479 & 0.6808 \\
\hline 5.0 & 0.75 & 0.5219 & 0.9581 & 0.7809 & 0.8162 & 0.8396 & 0.7045 \\
\hline 6.0 & 0.75 & 0.5183 & 0.9648 & 0.7840 & 0.8134 & 0.8338 & 0.7203 \\
\hline 3 & 0.55 & 0.5013 & 0.9973 & 0.7946 & 0.8053 & 0.8195 & 0.7768 \\
\hline 3 & 0.60 & 0.5054 & 0.9893 & 0.7889 & 0.8105 & 0.8353 & 0.7497 \\
\hline 3 & 0.65 & 0.5123 & 0.9759 & 0.7829 & 0.8159 & 0.8475 & 0.7186 \\
\hline 3 & 0.70 & 0.5225 & 0.9570 & 0.7764 & 0.8216 & 0.8559 & 0.6829 \\
\hline 3 & 0.75 & 0.5363 & 0.9322 & 0.7693 & 0.8279 & 0.8603 & 0.6419 \\
\hline 3 & 0.80 & 0.5548 & 0.9012 & 0.7614 & 0.8351 & 0.8602 & 0.5943 \\
\hline 3 & 0.85 & 0.5796 & 0.8626 & 0.7523 & 0.8441 & 0.8547 & 0.5379 \\
\hline 3 & 0.90 & 0.6144 & 0.8139 & 0.7414 & 0.8564 & 0.8420 & 0.4676 \\
\hline 3 & 0.95 & 0.6698 & 0.7465 & 0.7266 & 0.8764 & 0.8164 & 0.3690 \\
\hline
\end{tabular}

$\gamma$ is the measure of relative risk aversion, $q_{H}$ is the survival probability of the H-insureds, $q_{A D}$ is the survival probability used by the insurer, MWR is the money's worth ratio and $C_{t i}$ is the consumption level of $\mathrm{i}$-insureds $(\mathrm{i}=\mathrm{H}, \mathrm{L})$ at time $\mathrm{t}(\mathrm{t}=0,1)$. In all cases the high and low types are equally likely and the survival probabilities of the $\mathrm{H}$-insureds and L-insureds add up to 1 


\section{Multi-period simulations under the asymmetric equilibrium contract}

In the previous section we demonstrate in a simple two-period model that adverse selection in the annuity market has a minor impact on welfare. In the current section we present the corresponding multi-period model. The multi-period problem is different because insureds have less flexibility and cannot fully exploit the information regarding their type. The annuity contract usually limits its owner to either a fixed nominal, or an approximately fixed real, annual distribution. ${ }^{18}$ This structure is optimal for the fair annuity buyer. However, the H-insureds would like an increasing real annuity, while the L-insureds would like a decreasing real annuity. Thus, although the H-insureds buy the annuity after their type is revealed, they are limited to a contract with little flexibility so they cannot fully exploit their type information. ${ }^{19}$

Suppressing the type subscript, we denote by $q_{t}$ the death probability between age $t$ and age $t+1$ of an individual who is alive at age $t$. Consider an individual who contemplates the purchase of an immediate annuity contract at the retirement age of 65. Denote the survival probabilities at age 65 by $P_{1}, P_{2}, \ldots, P_{T}$, where $P_{1}=1$ is the probability to survive through age $65 ; P_{2}$ is the probability to survive through age 66; etc. We denote by $T$ the last period that an individual may be alive. Given the series $\left\{q_{t}\right\}, P_{2}=1-q_{65}, P_{i}=\left(1-q_{65}\right) *\left(1-q_{66}\right) \ldots *\left(1-q_{65+i-2}\right)$.

The insured may choose not to annuitize all his wealth, so in addition to the $a$ units of annuity that he purchases, he also buys a stream of non-annuitized income $b_{t}$. Thus, $C_{t}=a+b_{t}$ for all $\mathrm{t}$. In that case, the insured solves the following maximization problem:

$$
\begin{gathered}
\max \sum_{t=1}^{T} \beta^{t-1} P_{t} u\left(C_{t}\right) \\
\text { S.T. } C_{t}=a+b_{t} \\
W=P_{A} a+\sum_{t=1}^{T} b_{t}\left(\frac{1}{1+r}\right)^{t-1} \\
a, b_{t} \geq 0
\end{gathered}
$$

where $P_{A}$ is the equilibrium price of a one-dollar annuity. Based exclusively on the life table for the general population, the fair price of an annuity is: $P_{\text {Afair }}=\Sigma_{t=1}^{\mathrm{T}} P_{t}(1 /(1+r))^{t-1}$, where $P_{t}=1 / 2 P_{L t}+1 / 2 P_{H t}$, where $P_{L t}$ and $P_{H t}$ are the survival probabilities (the counterparts of $P_{t}$ ) for the L-insureds and the L-insureds, respectively. However, the annuity price $P_{A}$ that is consistent with the zero profit condition is higher than $P_{\text {Afair }}$ if the $\mathrm{H}$-insureds buy more annuities than the L-insureds. The Money's Worth Ratio mentioned above is now $M W R=P_{\text {Afair }} / P_{A}$.

\footnotetext{
${ }_{18}$ Annuities that increase in a fixed percentage are available in the U.K., and consist of about four percent of the annuities that are studied by Finkelstein and Poterba [2002].

${ }^{19}$ However, in our model the L-insureds procure a decreasing consumption stream by combining a fixed annuity with a decreasing stream of consumption that is generated by a non-annuitized financial asset.
} 
Table 3 Annuity levels, money's worth ratios, equivalent variations of asymmetric and no access cases under a multiple-period simulation

\begin{tabular}{lllllll}
\hline$\gamma$ & $P_{A}$ & $a_{H}=w / P_{A}$ & $a_{L}$ & MWR & $E V_{m u}$ & $E V_{\text {nо-mu }}$ \\
\hline 3.0 & 10.2730 & $0.0973 w$ & $0.0912 w$ & 0.9930 & 0.9949 & 0.7924 \\
1.5 & 10.3607 & $0.0965 w$ & $0.0837 w$ & 0.9846 & 0.9889 & 0.7226 \\
0.5 & 11.1645 & $0.0896 w$ & $0.0355 w$ & 0.9137 & 0.9393 & 0.6873 \\
\hline
\end{tabular}

$\gamma$ is the measure of relative risk aversion, $P_{A}$ is the equilibrium price of a one-dollar annuity, $a_{i}(\mathrm{i}=\mathrm{H}, \mathrm{L})$ is the annuity purchase of the i-insureds, MWR is the money's worth ratio, and $E V_{m u}$ and $E V_{n o-m u}$ are the ratios between the wealth under the first-best allocation and the wealth levels that yield the same welfare under the Asymmetric Information and No Access to Annuity Markets allocations, respectively

\subsection{The simulations}

We obtain the death probability, $q_{t}$, from the standard unisex life tables. ${ }^{20}$ These tables indicate that, for the general population, half of the agents that are alive at age 65 reach the age of 81 . We again assume two types of insureds, and set $q_{H t}=0.45 * q_{t}$, and $q_{L t}=2.07 * q_{t}$, making the H-insureds less likely to die and thus live longer than the L-insureds. The constants 0.45 and 2.07 are chosen to replicate the two-period model, with the resulting survival probabilities at age 81 equal to 0.25 for the L-insureds and 0.75 for the $\mathrm{H}$-insureds. The life expectancies as of age 65 for the two types also diverge significantly in a manner similar to the assumption in the two-period model: 23.9 years for the $\mathrm{H}$-insureds and 11.1 for the $\mathrm{L}$-insureds. We use the standard discount rate in the actuarial literature: six percent compounded annually.

The equilibrium value of $P_{A}$ is obtained by successive approximations, calculating the demand for annuities of both types, and then plugging them into the insurer's budget constraint, which is similar to the two-period model.

Table 3 presents the simulated annuity levels, the MWR values and the impacts of the asymmetric information on welfare for three alternative levels of the risk aversion parameter $\gamma$.

The H-insureds annuitize all their wealth while the L-insureds annuitize only a fraction of their wealth. This difference between the purchases of the $\mathrm{H}$ - and L-insureds accounts for the adverse selection. For $\gamma=3$ or even $\gamma=1.5$, this difference is not great, so that the MWR is close to one. However, for $\gamma=0.5$ the L-insureds annuitize only $40 \%$ of their wealth and the MWR drops to $91 \%$. We again compare the loss of expected utility from adverse selection to the corresponding loss when there is no access to the annuity market by contrasting the expected utility under these allocations with the expected utility under the precommitment contract. Note that the $E V_{M U}$ is, again, closer to 1 than the MWR, because the L-insureds substitute away from annuities when their price increases. The comparison of the equivalent variations in the two right-most columns in Table 3 indicates that the two-period model does not understate the welfare loss due to adverse selection relative to the loss due to no access to annuity markets. It also demonstrates that adverse selection and asymmetric information in the annuity

\footnotetext{
20 Bowers et al. [1986].
} 
market should not reduce welfare significantly. Because conclusions based on the allocation in the two-period model seem also to be valid for a multi-period case, in the next section we use the two-period model (in which calculating and presenting the allocation is relatively simple) to examine whether adverse selection could explain the lack of participation in the annuity market in the presence of a bequest motive and social security benefits.

\section{Adverse selection with a bequest motive}

In this section we incorporate a bequest motive into the two-period model. A bequest motive diminishes the loss when an individual who uses a non-annuitized financial asset $D$ does not survive till $t=2 .^{21}$

The model that incorporates a bequest motive is identical to the asymmetric information model described above with two exceptions. First, a bequest motive, denoted by $\delta$ appears in the utility of agents who die before date $t=2 .^{22}$ Second, we assume an equilibrium in which individuals optimally determine their demand for annuities, which depends on the strengths of their bequest motive and on their survival probabilities. Thus, we assume an economy in which individuals are characterized by both the strength of their bequest motive and their survival probability. We further assume that insurace companies either cannot observe these characteristics or, for other reasons, cannot use them to quote the premia for annuity contracts. We demonstrate that, in contrast to the no bequest case (where all agents purchase annuities), agents with sufficiently low expected longevity and a strong bequest motive do not purchase annuities. We find a threshold value for the parameter representing the strength of the bequest motive, denoted by $\delta^{\prime}$, that depends on the equilibrium price of annuities and the survival probability of the agent. Individuals purchase annuities if and only if their bequest motive parameter is below $\delta^{\prime}$. We show that this behavior may lead to non-existence of equilibrium in the continuous distribution case. ${ }^{23}$

We first simulate the equilibrium by using the CRRA utility function, and a discrete approximation of a joint uniform distribution for the survival probability and the bequest motive parameter. ${ }^{24}$ In this equilibrium, much as in reality, a large proportion of the agents does not participate in the annuities market. Thus, we calculate two MWR measures: one relative to the life table of the general population and the other relative to the life table of annuitants. Although these MWRs are considerably lower than the corresponding values obtained in the previous sections, the expected welfare loss is still very small.

\footnotetext{
21 The literature concerning the strength of a bequest motive is not yet conclusive. Hurd [1989] claims that it is weak, while Bernhein [1991] concludes that it is strong. Gan et al. [2004] find a very weak bequest motive when they use median regressions, but a strong bequest motive when they use mean regressions.

22 For a discussion of the modeling of a bequest motive, see Abel and Warshawsky [1988].

23 More formally, only the group of agents with the highest survival probability purchases annuities.

24 Compared with a distribution that has only two survival types and two bequest strengths, the assumed joint uniform distribution better facilitates an equilibrium in which individuals with different survival probabilities purchase annuities while some individuals do not purchase annuities at all.
} 
We assume again, that insureds can invest in two assets: a regular, nonannuitized, financial asset $D$ and an annuity $A$, with the respective prices $P_{D}=1 /(1+r)$ and $P_{A}=q_{A D} /(1+r)$. The annuity price is lower because $q_{A D}<1$; hence, the only rationale for holding the non-annuitized asset is the desire to leave a bequest in the event of death before $t=2$.

We assume that agents evaluate the utility of their heirs by the same utility function as their own, except that they apply a discount factor $\delta_{j}, 0 \leq \delta_{j} \leq 1$. We assume $m$ possible values for $\delta_{j}$ and $n$ possible values for the survival probability $q_{i}$. Thus, each agent is characterized as belonging to one of $n * m$ equally likely types. Recall that the wealth level $W$ is assumed to be 1 , and that the subjective discount factor $\beta$ is assumed to equal $1 /(1+r)$. The agent's maximization problem is:

$$
\begin{gathered}
\max u\left(C_{1 i j}\right)+\beta\left[q_{i} u\left(C_{2 i j}\right)+\left(1-q_{i}\right)_{j} u\left(B_{i j}\right)\right] \\
\text { s.t. } C_{1 i j}+A_{i j} P_{A}+D_{i j} P_{D}=1 \\
C_{2 i j}=A_{i j}+D_{i j} \\
B_{i j}=D_{i j} \\
i=1, \ldots, n, j=1, \ldots, m .
\end{gathered}
$$

The budget constraint may also be written as:

$$
C_{1 i j}+C_{2 i j} q_{A D} /(1+r)+B_{i j}\left(1-q_{A D}\right) /(1+r)=1 .
$$

Since $u^{\prime}(0)$ is unbounded, the bequest $B_{i j}$ vanishes if and only if $\delta_{j}=0$.

To derive the first order conditions and solve for the optimum, we distinguish between two cases: $A>0$ and $A=0$.

Case 1: $A>0$.

$$
\begin{gathered}
u^{\prime}\left(C_{2 i j}\right)=u^{\prime}\left(C_{1 i j}\right) q_{A D} / q_{i} . \\
\delta_{j} u^{\prime}\left(B_{i j}\right)=u^{\prime}\left(C_{1 i j}\right)\left(1-q_{A D}\right) /\left(1-q_{i}\right) .
\end{gathered}
$$

Case 2: $A=0$.

$$
\begin{gathered}
B_{i j}=C_{2 i j} . \\
u^{\prime}\left(B_{i j}\right)=u^{\prime}\left(C_{1 i j}\right) /\left(q_{i}+\delta_{j}\left(1-q_{i}\right)\right) .
\end{gathered}
$$

These conditions, in conjunction with the budget constraint, yield solutions for the consumption and bequest levels as functions of $q_{A D}$. When $\delta$ is sufficiently large, $A$ vanishes. The threshold value of $\delta$, denoted as $\delta^{\prime}$, is found when the solutions of the two cases have the same value. Hence:

$$
\delta^{\prime}=\left(\left(1 / q_{A D}\right)-1\right) /\left(\left(1 / q_{i}\right)-1\right) .
$$

It follows that:

$$
\text { for } \delta_{j}<\delta^{\prime}, A_{i}>0 \text {, and for } \delta_{j} \geq \delta^{\prime}, A_{i}=0 \text {. }
$$


Table 4 Asymmetric information with bequest: annuity purchases and equivalent variations

\begin{tabular}{|c|c|c|c|c|c|c|c|c|c|c|c|c|c|}
\hline \multicolumn{14}{|c|}{$q_{A D}=.684 M W R=.731$} \\
\hline$q$ & $\delta$ & 0 & 0.1 & 0.2 & 0.3 & 0.4 & 0.5 & 0.6 & 0.7 & 0.8 & 0.9 & 1.0 & $\delta^{\prime}$ \\
\hline 0.1 & & 0.45 & 0 & 0 & 0 & 0 & 0 & 0 & 0 & 0 & 0 & 0 & 0.05 \\
\hline 0.2 & & 0.54 & 0.02 & 0 & 0 & 0 & 0 & 0 & 0 & 0 & 0 & 0 & 0.12 \\
\hline 0.3 & & 0.60 & 0.11 & 0 & 0 & 0 & 0 & 0 & 0 & 0 & 0 & 0 & 0.20 \\
\hline 0.4 & & 0.65 & 0.19 & 0.08 & 0.01 & 0 & 0 & 0 & 0 & 0 & 0 & 0 & 0.31 \\
\hline 0.5 & & 0.69 & 0.26 & 0.16 & 0.08 & 0.03 & 0 & 0 & 0 & 0 & 0 & 0 & 0.46 \\
\hline 0.6 & & 0.72 & 0.32 & 0.23 & 0.16 & 0.11 & 0.07 & 0.03 & 0 & 0 & 0 & 0 & 0.69 \\
\hline 0.7 & & 0.75 & 0.39 & 0.30 & 0.24 & 0.19 & 0.16 & 0.12 & 0.09 & 0.06 & 0.04 & 0.02 & 1.08 \\
\hline 0.8 & & 0.77 & 0.46 & 0.38 & 0.33 & 0.29 & 0.25 & 0.22 & 0.20 & 0.17 & 0.15 & 0.13 & 1.85 \\
\hline 0.9 & & 0.80 & 0.55 & 0.49 & 0.44 & 0.41 & 0.38 & 0.36 & 0.33 & 0.31 & 0.30 & 0.28 & 4.16 \\
\hline & & & & & & & & & & & & & average \\
\hline$E V_{b}$ & & 0.94 & 0.98 & 0.99 & 1.00 & 1.00 & 1.00 & 1.00 & 1.00 & 1.00 & 1.00 & 1.00 & 0.99 \\
\hline$E V_{n o-b}$ & & 0.83 & 0.87 & 0.90 & 0.92 & 0.94 & 0.95 & 0.97 & 0.98 & 0.99 & 0.99 & 1.00 & 0.94 \\
\hline
\end{tabular}

The table presents an equilibrium solution for the ninety nine participants in the market for a measure of relative risk aversion $(\gamma)$ of 3 . For each participant, with a survival probability (q) and a bequest motive $(\delta)$, the entry represents her annuity purchase. $q_{A D}$ is the survival probability used by the insurer and MWR is the money's worth ratio. $\delta^{\prime}$ is the highest value for the parameter indicating the strength of the bequest motive for individuals who purchase annuities. $E V_{b}$ and $E V_{n o-b}$ are the ratios between the wealth under the first-best allocation and the wealth levels that yield the same welfare under the Asymmetric Information and No Access to Annuity Markets allocations, respectively

The insurance industry equilibrium condition is:

$$
\Sigma_{i=1, \ldots, n j=1, \ldots, m} A_{i j} q_{i}=q_{A D} \sum_{i=1, \ldots, n j=1, \ldots, m} A_{i j} .
$$

\subsection{Simulation of the model}

We use the same CRRA utility function as in the previous sections. ${ }^{25}$ Agents participate in the annuity market if and only if their bequest strength parameter, $\delta$, is below the critical value $\delta^{\prime}$ (which depends on $q_{i}$ and $q_{A D}$ ). In the simulations we determine $\delta^{\prime}$ and $q_{A D}$ simultaneously.

We assume that $q_{i}$ and $\delta_{j}$ are distributed evenly on the interval [0,1]. For the purposes of the calculation we approximate the distribution by ten intervals. The values $q=0$ and $q=1$ are trivial in our framework, hence we consider only nine possible values for $q_{i}: q_{i}=0.1,0.2, \ldots, 0.9$. We consider eleven possible values for $\delta_{j}: \delta_{j}=0,0.1, \ldots, 1.0$ (i.e., $n=9$ and $m=11$ ), yielding ninety-nine distinct groups of individuals.

In Table 4 we report the results of the simulation of the equilibrium for the base value of $\gamma=3$. The introduction of a bequest motive intensifies the adverse selection as measured by $q_{A D}$ and MWR. Table 4 presents the demand for annuity for each agent type (i.e., a combination of $q_{i}$ and $\delta_{j}$ ). In the last column we present the

\footnotetext{
25 The details of the calculations are reported in the Appendix of the full version of the article obtainable from the authors upon request.
} 
threshold value of $\delta^{\prime}$ for each $q_{i}$. We note that only 54 of the 99 agent types $(54.5 \%)$ participate in the market. We also present the equivalent variations for insureds and for agents who do not have access to annuity markets.

The average equivalent variation for insureds with a given $\delta_{j}$ is presented in the second row from the bottom of Table 4. At date 0 , before the survivorship probability is revealed, the equilibrium includes eleven types of agents with values of a bequest motive $\left(\delta_{j}\right)$ between zero and one. For each type we calculate the Equivalent Variation (i.e., the level of wealth under a precommitment contract that yields the same level of expected utility as generated by a $\$ 1$ wealth under the asymmetric information contract).

We find that the welfare loss due to asymmetric information is the largest for agents with no bequest motive at all (about 6\% loss). For almost all other agents it is equivalent to a loss of less than one percent of wealth. A closer examination reveals that the demand for annuities by agents with a positive bequest parameter is very sensitive to the survival probability. When the survival probability is low, agents annuitize only a small portion of their savings and leave most of it in bequeathable form. The bequest is like a private annuity arrangement that is agreed upon with the heirs. Under asymmetric information this arrangement is a substitute for the public annuities market. If the agent survives to period 2, she will consume this wealth; if the agent does not survive, the heirs will inherit it. ${ }^{26}$

Agents with a bequest parameter larger than six-tenths purchase annuities only if the realization of their $q_{i}$ is larger than $0.7 .^{27}$ Consequently, the adverse selection in the annuities market serves to transfer welfare from agents with a low bequest motive to those with a high bequest motive.

The last row of Table 4 presents the corresponding equivalent variations for the individuals with a bequest motive who do not have access to annuity markets. The welfare loss due to lack of access to an annuity market is still substantially larger than the loss of welfare due to adverse selection. However, both are considerably smaller than the corresponding losses when individuals have no bequest motive.

Note that the existence of a bequest motive aggravates the non-welfare measures of adverse selection. The equilibrium in this model yields higher values of $q_{A D}$ and lower values of MWR than their counterparts in the no-bequest models studied in the previous sections. However, if we construct the life table of participating agents only, the figures change significantly. We define an indicator function: $a_{i j}=\{1$ whenever $A_{i j}>0$ and 0 whenever $A_{i j}=0$. We calculate $q_{\text {particp }}$ as the average $q_{i}$ within the group of the participating agents:

$$
q_{\text {particp }}=\left\lfloor\sum_{\substack{i=1 \ldots n \\ j=1 \ldots m}} a_{i j} q_{i}\right\rfloor /\left\lfloor\sum_{\substack{i=1 \ldots n \\ j=1 \ldots m}} a_{i j}\right\rfloor .
$$

\footnotetext{
26 This point is elaborated upon in Kotlikoff and Spivak [1981].

27 That is, the adverse selection induces agents with a strong bequest motive and a low or moderate survival probability to prefer holding a non-annuitized asset that can be left to their heirs over purchasing an annuity. In contrast, agents with high survival probabilities (i.e., that exceed $q_{A D}$ ) can only gain from the annuities market. Note that in our simulations $q_{A D}$ is less than 0.7 .
} 
Table 5 Measures of adverse selection for alternative values of the risk parameter $\gamma$

\begin{tabular}{lllll}
\hline$\gamma$ & $q_{A D}$ & MWR & q $_{\text {particp }}$ & MWR $^{\prime}$ \\
\hline 0.5 & 0.789 & 0.633 & 0.693 & 0.878 \\
2.0 & 0.709 & 0.705 & 0.667 & 0.941 \\
3.0 & 0.684 & 0.731 & 0.663 & 0.970 \\
5.0 & 0.651 & 0.768 & 0.652 & 1.001 \\
\hline
\end{tabular}

$\gamma$ is the measure of relative risk aversion, $q_{A D}$ is the survival probability used by the insurer, MWR is the money's worth ratio, $q_{\text {particp }}$ is the average $q_{i}$ within the group of the participating agents and $\mathrm{MWR}^{\prime}$ is the value of MWR relative to $\mathrm{q}_{\text {particp }}$

We denote by MWR' the money worth ratio for the individuals who participate in the annuity market (i.e., $q_{\text {particp }} / q_{A D}$ ). Table 5 reports the results for alternative values of the risk parameter $\gamma$. The annuity cost declines and the $\mathrm{MWR}^{\prime}$ increases as $\gamma$ increases. For the sufficiently high value of $\gamma=5$, the $\mathrm{MWR}^{\prime}$ even exceeds $1 .^{28}$

\subsection{An example of the non-existence of equilibrium}

In another simulation we approximate a uniform distribution for $q$ on the interval $[0,1]$ by assuming 5001 equally-spaced possible realizations, but assume an identical bequest parameter for all agents. Assuming that $\gamma=3$, an equilibrium in which some agents purchase annuities exists for values of $\delta$ below 0.275 . For values of $\delta$ exceeding 0.28 , the only equilibrium we find is when $q_{A D}=1$, and agents with $q=1$ are indifferent between purchasing annuities and not purchasing them.

We conclude that the existence of a bequest motive reduces the demand for annuities. We demonstrate the existence of an equilibrium in which some, but not all, individuals purchase annuities. Furthermore, we demonstrate that a strong enough bequest motive may completely eliminate the market for annuities. However, the welfare loss is rather small regardless of whether agents purchase annuities or avoid the annuity market because a bequest is a private substitute for annuities.

\section{Adverse selection in the presence of mandatory social security annuity insurance}

The annuity market may be influenced also by the existence of a mandatory social security annuity insurance. To assess its impact, we modify the basic adverse selection model given in Sect. 2 to allow for the existence of a self-financing social security system. Each insured now receives a retirement pension of $\mathrm{S}$ upon

\footnotetext{
${ }^{28}$ This is not a computation error. Note that, among annuitants, the average annuity purchase of agents with $\mathrm{q}_{\mathrm{i}}=.1$ (only those with $\delta=0$ are annuitants) is 0.45 . The corresponding average for agents with $\mathrm{q}_{\mathrm{i}}=$ .9 is 0.42 . Thus, considering annuitants only, the average annuity purchased is not necessarily increasing in $\mathrm{q}_{\mathrm{i}}$. Consequently, the weighted average of the $\mathrm{q}_{\mathrm{i}}$ 's of annuitants with the $A_{i j}$ 's serving as weights $\left(=\mathrm{q}_{A D}\right)$ may be lower than the simple average of the $\mathrm{q}_{\mathrm{i}}$ 's of annuitants $\left(=\mathrm{q}_{\mathrm{particp}}\right)$. Thus, $M W R^{\prime}=q_{p a r t i c p} / q_{A D}>1$. This is another indication that MWRs do not always reflect welfare loss.
} 
surviving to the second period. Since the social security system is universal and egalitarian, every individual pays a social security tax of $S /(2(1+r))$. These changes are reflected in the insureds' problem below:

$$
\begin{gathered}
\max u\left(C_{1 i}\right)+q_{i} \beta u\left(C_{2 i}\right) \\
\text { s.t. } C_{1 i}+\left(C_{2 i}-S\right) q_{A D} /(1+r)=1-S /(2(1+r)) \\
i=H, L .
\end{gathered}
$$

Consistent with Walliser [2000], the existence of a social security system accentuates the adverse selection problem. Insureds now obtain their retirement income from two sources: the fixed publicly- provided pension $S$, and the privatelyprovided annuity $C_{2 i}-S$. The ratio of $\left(C_{2 L}-S\right) /\left(C_{2 H}-S\right)$ is negatively related to $S$, and hence the adverse selection problem is exacerbated with the expansion of the social security system. The simulation results for our base case, $\gamma=3$ and $\mathrm{q}_{\mathrm{H}}=0.75$, when several alternative levels of social security benefits are availabe, are presented in Table 6.

The money's worth ratio declines from 0.93 to 0.76 as $S$ increases from 0 to 0.55 . Recall that the maximal level of social security benefits is 0.8 , the consumption level under the precommitment allocation. For $S \geq .6$, the L-insureds do not purchase annuities in the private sector at all, while the $\mathrm{H}$-insureds purchase fairly priced annuities. Our calculations (presented in the second column from the right)

Table 6 Money's worth ratios, consumption levels, and equivalent variations in the presence of social security benefits

\begin{tabular}{llllllll}
\hline Social Security Benefit (S) & MWR & $C_{1 H}$ & $C_{1 L}$ & $C_{2 H}$ & $C_{2 L}$ & $E V_{s s}$ & $E V_{\text {no-ss }}$ \\
\hline 0.0000 & 0.9322 & 0.7693 & 0.8279 & 0.8603 & 0.6419 & 0.9933 & 0.8545 \\
0.0500 & 0.9278 & 0.7695 & 0.8282 & 0.8591 & 0.6411 & 0.9933 & 0.8652 \\
0.1000 & 0.9227 & 0.7697 & 0.8286 & 0.8578 & 0.6403 & 0.9933 & 0.8759 \\
0.1500 & 0.9168 & 0.7699 & 0.8291 & 0.8562 & 0.6393 & 0.9933 & 0.8866 \\
0.2000 & 0.9099 & 0.7702 & 0.8296 & 0.8544 & 0.6381 & 0.9933 & 0.8972 \\
0.2500 & 0.9017 & 0.7706 & 0.8303 & 0.8522 & 0.6367 & 0.9933 & 0.9079 \\
0.3000 & 0.8918 & 0.7710 & 0.8311 & 0.8495 & 0.6350 & 0.9932 & 0.9186 \\
0.3500 & 0.8796 & 0.7715 & 0.8321 & 0.8461 & 0.6328 & 0.9932 & 0.9293 \\
0.4000 & 0.8638 & 0.7721 & 0.8334 & 0.8418 & 0.6300 & 0.9931 & 0.9400 \\
0.4500 & 0.8428 & 0.7730 & 0.8352 & 0.8359 & 0.6262 & 0.9929 & 0.9507 \\
0.5000 & 0.8126 & 0.7744 & 0.8379 & 0.8272 & 0.6206 & 0.9926 & 0.9613 \\
0.5500 & 0.7626 & 0.7766 & 0.8425 & 0.8121 & 0.6109 & 0.9919 & 0.9720 \\
0.6000 & 0.6667 & 0.7818 & 0.8500 & 0.7818 & 0.6000 & 0.9906 & 0.9812 \\
0.6500 & 0.6667 & 0.7864 & 0.8375 & 0.7864 & 0.6500 & 0.9951 & 0.9885 \\
0.7000 & 0.6667 & 0.7909 & 0.8250 & 0.7909 & 0.7000 & 0.9979 & 0.9942 \\
0.7500 & 0.6667 & 0.7955 & 0.8125 & 0.7955 & 0.7500 & 0.9995 & 0.9984 \\
\hline
\end{tabular}

$\mathrm{S}$ is the level of social security benefits. MWR is the money's worth ratio, $C_{t i}$ is the consumption level of the $\mathrm{i}$-insureds $(\mathrm{i}=\mathrm{H}, \mathrm{L})$ at time $\mathrm{t}(\mathrm{t}=0,1) . E V_{s s}$ and $E V_{\text {no-ss }}$ are the ratios between the wealth under the first-best allocation and the wealth levels that yield the same welfare under the Asymmetric Information and No Access to Annuity Markets allocations, respectively 
show, however, that the welfare loss due to asymmetric information in the presence of social security benefits is still less than one percent. However, the welfare loss due to the absence of an annuity market is much smaller than under the base case without a social security system. Even though, for $S \leq .4$ the welfare loss due to asymmetric information is still about one tenth of the corresponding loss of welfare due to an absence of access to annuity markets (presented in the right-most column).

Interestingly, our simulations indicate that having a modest social security system may be worse than having none. Although a social security system provides fair annuities, it also intensifies the adverse selection problem. We find that for a modest social security system the negative welfare impact of the increased adverse selection dominates the positive welfare impact of the provision of fairly priced annuities.

\section{Conclusion}

In this paper we investigate the effect of adverse selection on the functioning of the market for annuities and the resulting welfare implications. Deferred annuities and Defined Benefits pensions are contracted when insureds have little private information regarding their survival probabilities. By contrast, owners of Defined Contribution contracts (and possibly the proposed privatized portion of the Social Security system) determine their annuities when they retire. At that time they usually have more precise estimates of their survival probabilities. Because insurers either do not know these estimates or are prohibited from using them to set premiums, adverse selection of insureds is introduced into the market.

In principle, the best way to avoid adverse selection is by contracting before the information becomes known, as is shown by Brugiavini [1993] and Hirshleifer [1971]. However, a closer examination shows that the quantitative impact of adverse selection on insureds' welfare is rather limited. Using multi-period simulations of the insureds' behavior, we find that for most parameter values the induced welfare loss is equivalent to a loss of less than one percent of wealth, and is less than one tenth of the corresponding welfare loss due to a lack of access to annuity markets. We find a similar relationship between the magnitudes of the welfare losses due to adverse selection and the lack of access to annuity markets in all our simulations.

We examine the robustness of our results by incorporating a bequest motive and a social security system. The existence of a bequest motive reduces the demand for annuities. We demonstrate the existence of an equilibrium in which some, but not all, individuals purchase annuities. Furthermore, we demonstrate that a strong enough bequest motive may completely eliminate the market for annuities. However, the welfare loss is rather small because a bequest is a private substitute for annuities. We find that the importance of the market for annuities diminishes also due the incorporation of a social security system, another substitute for annuities. While adverse selection is intensified in both cases, the overall welfare losses due to adverse selection (as measured by equivalent variation wealth) for most parameter values remain equivalent to a wealth loss of less than one percent. Interestingly, our simulations indicate that having a modest social security system may be worse than having none. That is, for a modest social security system (i.e., benefit levels that are 
consistent with most social security systems) the negative welfare impact of the increased adverse selection dominates the positive welfare impact of the provision of fairly priced annuities.

We conclude that the effect of adverse selection on annuitants' welfare is very limited. In the absence of substitutes for annuities the adverse selection problem is not subtantial because all individuals choose to purchase annuities. Although subtitutes such as a bequest motive or a social security system worsen the adverse selection problem, the existence of a bequest motive more than compensates most annuitatnt in terms of welfare loss. The existence of a social security system partially offsets the welfare loss from the aggravated adverse selection problem.

Our findings are in line with the empirical analysis of annuity markets in the U.S. as well as in other countries. Mitchell et al. [1999] find that annuity prices are higher than the no-administrative-cost fair insurance by six to ten percent. However, they note that this margin is only an upper bound for the impact of adverse selection because it also includes "marketing cost, corporate overhead and income taxes, additions to various company contingency reserves, and profits" (p. 1300).

Acknowledgements We thank Jeff Brown, Estelle James, Olivia Mitchell, Dan Peled, Eytan Sheshinski, Ben Sopranzetti, John Wald, Mark Warshawsky, David Wettstein and participants of seminars at Bar-Ilan, Hebrew and Rutgers Universities for helpful comments. Palmon acknowledges the financial support of the Sanger Family Chair for Banking and Risk Management.

\section{Appendix}

Table A1 presents the Equivalent Variations that equal the pre-commitment wealth levels that provide the same expected utility levels as provided by wealth of $\$ 1$ under the adverse selection contract and in the absence of access to annuity markets for combinations of parameter values that are not used in the paper. It demonstrates that our results are robust to some of our simplifying assumptions.

Table A1 Equivalent variations of adverse selection: sensitivity to simplifying assumptions

\begin{tabular}{lllllll}
\hline & $\mathrm{r}$ & $\operatorname{Pr}\left(q_{H}\right)$ & $q_{H}$ & $q_{L}$ & $\mathrm{EV}_{\mathrm{ad}}$ & $\mathrm{EV}_{\text {no-ad }}$ \\
\hline Base Case & 1 & 0.5 & 0.75 & 0.25 & 0.9933 & 0.8545 \\
From Table 1: Low q $\mathrm{q}_{\mathrm{H}}$ High $\mathrm{q}_{\mathrm{L}}$ & 1 & 0.5 & 0.55 & 0.45 & 0.9997 & 0.8468 \\
From Table 1: High $\mathrm{q}_{\mathrm{H}}$ Low q & 1 & 0.5 & 0.95 & 0.05 & 0.9770 & 0.8858 \\
Lower r & 0.5 & 0.5 & 0.75 & 0.25 & 0.9921 & 0.8228 \\
Higher r & 2 & 0.5 & 0.75 & 0.25 & 0.9949 & 0.8930 \\
Lower Pr $\left(\mathrm{q}_{\mathrm{H}}\right)$ & 1 & 0.4 & 0.75 & 0.25 & 0.9930 & 0.8417 \\
Higher Pr $\left(\mathrm{q}_{\mathrm{H}}\right)$ & 1 & 0.6 & 0.75 & 0.25 & 0.9941 & 0.8674 \\
Lower $\mathrm{q}_{\mathrm{H}}$ & 1 & 0.5 & 0.55 & 0.25 & 0.9968 & 0.8252 \\
Higher $\mathrm{q}_{\mathrm{H}}$ & 1 & 0.5 & 0.95 & 0.25 & 0.9898 & 0.8864 \\
Lower $\mathrm{q}_{\mathrm{L}}$ & 1 & 0.5 & 0.75 & 0.05 & 0.9821 & 0.8542 \\
Higher $\mathrm{q}_{\mathrm{L}}$ & 1 & 0.5 & 0.75 & 0.45 & 0.9981 & 0.8763 \\
\hline
\end{tabular}


Table A1 continued

\begin{tabular}{lllllll}
\hline & $\mathrm{r}$ & $\operatorname{Pr}\left(q_{H}\right)$ & $q_{H}$ & $q_{L}$ & $\mathrm{EV}_{\mathrm{ad}}$ & $\mathrm{EV}_{\text {no-ad }}$ \\
\hline Lower $\mathrm{q}_{\mathrm{H}}$ and $\mathrm{q}_{\mathrm{L}}$ & 1 & 0.5 & 0.55 & 0.05 & 0.9873 & 0.8257 \\
Higher $\mathrm{q}_{\mathrm{H}}$ and $\mathrm{q}_{\mathrm{L}}$ & 1 & 0.5 & 0.95 & 0.45 & 0.9959 & 0.9083 \\
Lower $\operatorname{Pr}\left(\mathrm{q}_{\mathrm{H}}\right)$ and $\mathrm{q}_{\mathrm{H}}$ & 1 & 0.4 & 0.55 & 0.25 & 0.9967 & 0.8183 \\
Lower $\operatorname{Pr}\left(\mathrm{q}_{\mathrm{H}}\right)$ and Higher $\mathrm{q}_{\mathrm{H}}$ & 1 & 0.4 & 0.95 & 0.25 & 0.9892 & 0.8672 \\
Lower $\operatorname{Pr}\left(\mathrm{q}_{\mathrm{H}}\right)$ and $\mathrm{q}_{\mathrm{L}}$ & 1 & 0.4 & 0.75 & 0.05 & 0.9808 & 0.8427 \\
Lower $\operatorname{Pr}\left(\mathrm{q}_{\mathrm{H}}\right)$ and Higher $\mathrm{q}_{\mathrm{L}}$ & 1 & 0.4 & 0.75 & 0.45 & 0.9981 & 0.8677 \\
Higher $\operatorname{Pr}\left(\mathrm{q}_{\mathrm{H}}\right)$ and Lower $\mathrm{q}_{\mathrm{H}}$ & 1 & 0.6 & 0.55 & 0.25 & 0.9971 & 0.8321 \\
Higher $\operatorname{Pr}\left(\mathrm{q}_{\mathrm{H}}\right)$ and Higher $\mathrm{q}_{\mathrm{H}}$ & 1 & 0.6 & 0.95 & 0.25 & 0.9910 & 0.9057 \\
Higher $\operatorname{Pr}\left(\mathrm{q}_{\mathrm{H}}\right)$ and Lower $\mathrm{q}_{\mathrm{L}}$ & 1 & 0.6 & 0.75 & 0.05 & 0.9842 & 0.8663 \\
\hline
\end{tabular}

The Table presents the wealth under the precommitment contract that yields the same welfare as one unit of wealth under the Asymmetric Information contract $\left(\mathrm{EV}_{\mathrm{ad}}\right)$ and when individuals have no access to annuity markets $\left(\mathrm{EV}_{\mathrm{no}-\mathrm{ad}}\right)$ for alternative values of the discount rate $\mathrm{r}$, the probabilities of the high survival type, $\operatorname{Pr}\left(q_{H}\right)$, and the values of the high and low survival probabilities, $q_{H}$ and $q_{L}$. The measure of relative risk aversion equals 3 in all cases

\section{References}

AARON, H.J. (Ed.) [1999]: Behavioral Dimensions of Retirement Economics, Washington: Brookings. ABEL, A.B. [1986]: "Capital Accumulation and Uncertain Lifetime with Adverse Selection," Econometrica, 54, 1079-1098.

ABEL, A.B. and WARSHAWSKY, M.J. [1988]: "Specification of the Joy of Giving: Insights from Altruism," Review of Economics and Statistics, 70(1), 145-149.

AKERLOFF, G. [1970]: "The Market for Lemons: Quality Uncertainty and the Market Mechanism," Quarterly Journal of Economics, 89, 488-500.

ALTONJI, J., HAYASHI, F., and KOTLIKOFF, L.J. [1997]: "Parental Altruism and Inter Vivos Transfers: Theory and Evidence," Journal of Political Economy, 105(6), 1121-1166.

BERNHEIM, B.D. [1991]: "How Strong Are Bequest Motives? Evidence Based on Estimates of the Demand for Life Insurance and Annuities,” Journal of Political Economy, 99(5), 899-927.

BOWERS, N.L., GERBER, H.U., HICKMAN, J.C., JONES, D.A., and NESBITT, C.J. [1986]: Actuarial Mathematics, Itasca, Illinois: The Society of Actuaries.

BROWN, J.R. [2003]: "Redistribution and Insurance: Mandatory Annuitization With Mortality Heterogeneity," Journal of Risk and Insurance, 70(1), 17-41.

BRUGIAVINI, A. (1993): "Uncertainty Resolution and the Timing of Annuity Purchases," Journal of Public Economics, 50, 31-62.

CROCKER, K.J. and SNOW, A. [1992]: "The Social Value of Hidden Information in Adverse Selection Economies," Journal of Public Economics, 48, 317-347.

DAVIDOFF, T., BROWN, J.R., and DIAMOND, P.A. [2005]: “Annuities and Individual Welfare," American Economic Review, 95(5), 1573-1590.

DIAMOND, P.A. [1994]: "Privatization of Social Security: Lessons from Chile," Revista de Analisis Economico, 9, 21-23 in P. DIAMOND, D. LINDEMAN, and YOUNG, H. (Eds.) (revised version in1996) Social Security: What Role for the Future?. Washington: Brookings.

DUSHI, I. and WEBB, A. [2004]: “Annuitization: Keeping Your Options Open,” Center for Retirement Research at Boston College Working Paper 2004-04; SSRN abstract=546629.

ECKWERT, B. and ZILCHA, I. [2003]: "Incomplete Risk Sharing and the Value of Information," Economic Theory, 21(1), 43-58.

EICHENBAUM, M.S. and PELED, D. [1987]: "Capital Accumulation and Annuities in an Adverse Selection Economy," Journal of Political Economy, 95, 334-354.

EPSTEIN, L.G. and ZIN, S.E. [1989]: "Substitution, Risk Aversion, and the Temporal Behavior of Consumption and Asset Returns: A Theoretical Framework," Econometrica, 57(4), 937-969. 
FELDSTEIN, M. and RANGUELOVA, E. [2001]: "Individual Risk in an Investment-Based Social Security System,” American Economic Review, 91(4), 1116-1125.

FINKELSTEIN, A. and POTERBA, J.M. [2002]: "Selection Effects in the United Kingdom Individual Annuities Market," Economic Journal, 112, 28-50.

FINKELSTEIN, A. and POTERBA, J.M. [2004]: "Adverse Selection in Insurance Markets: Policyholders Evidence From the UK Annuity Market," Journal of Political Economy, 112(1) Part 1, 183-208.

FONG, W.M. [2002]: “On the Cost of Adverse Selection in Individual Annuity Markets: Evidence from Singapore," The Journal of Risk and Insurance, 69(2), 193-207.

FRIEDMAN, B. and WARSHAWSKY, M.J. [1990]: “The Cost of Annuities: Implications for Saving Behavior and Bequests," Quarterly Journal of Economics, 105, 135-154.

GAN, L., GONG, G., HURD, M., and MCfADDEN, D. [2004]: "Subjective Mortality Risk and Bequests," National Bureau of Economic Research, Working Paper 10789 http://www.nber.org/ papers/w10789.

HIRSHLEIFER, J. [1971]: "The Private and Social Value of Information and the Reward to Incentive Activity," American Economic Review, 61, 561-574.

HURD, M.D. [1989]: “Mortality Risks and Bequests," Econometrica, 57, 779-813.

JAMES, E. and VITTAS, D. [2001]: “Annuities Markets in Comparative Perspective: Do Consumers Get Their Money's Worth?” in Private Pensions Systems: Administrative Costs and Reforms, Paris: OECD.

KOTLIKOFF, L.J. and SPIVAK, A. [1981]: “The Family as an Incomplete Annuities Market,” Journal of Political Economy, 89, 372-391.

KOTLIKOFF, L.J., SMETTERS, K., and WALLISER, J. [2004]: "Opting Out of Social Security," Journal of Public Economics, 88, 1295-1306.

MITCHELL, O.S. and McCARTHY, D.G. [2002]: "Estimating International Adverse Selection in Annuities," North American Actuarial Journal, 6, 38-54.

MITCHELL, O.S., POTERBA, J.M., WARSHAWSKY, M.J., and BROWN, J.R. [1999]: "New Evidence on the Money's Worth of Individual Annuities," American Economic Review, 89, 1299-1318.

MITCHELL, O.S. and UTKUS, S.P. (Eds.) [2004]: Pension Design and structure: New Lessons from Behavioral Finance, Pension Research Council. Oxford, UK: Oxford University Press.

POTERBA, J.M. [2001]: “Annuity Markets and Retirement Security,” Fiscal Studies, 22, 249-270.

SHESHINSKI, E. [2003]: “Annuities and Retirement," in Assets, Beliefs, and Equilibria in Economic Dynamics, D. Aliprantis, K.J. Arrow, P. Hammond, F. Kubler, H.M. WU, and N. Yannelis (Eds.), Springer, pp. 27-54.

STIGLITZ, J.E. [1988]: Economics of the Public Sector, New York: WW Norton \& Company.

TURRA, C.M. and MITCHELL, O.S. [2004]: "The Impact of Health Status and Out-of-Pocket Medical Expenditures on Annuity Valuation," University of Pennsylvania, Wharton School, Pension Research Council WP 2004-2.

WALLISER, J. [2000]: "Adverse Selection in the Annuities Market and the Impact of Privatizing Social Security,” Scandinavian Journal of Economics, 102(3), 373-393.

WARSHAWSKY, M.J. [1988]: "Private Annuity Markets in the United States: 1919-1984," Journal of Risk \& Insurance, 55, 518-528.

YAGI, T. and NISHIGAKI, Y. [1993]: “The Inefficiency of Private Constant Annuities,” Journal of Risk and Insurance, 60, 385-412.

YAARI, M.E. [1965]: "Uncertain Lifetime, Life Insurance and the Theory of the Consumer," Review of Economic Studies, 32, 137-150. 